\title{
Estudi de l'efecte de diversos factors sobre el contingut de vitamina C del suc de taronja
}

\author{
José Ángel Hernández Santadaría \\ Institut Badalona VII \\ jherna24@xtec.cat
}

El contingut de vitamina $C$ en sucs de fruita es pot determinar mitjançant una volumetria redox amb el colorant 2,6-diclorofenol indofenol. Aquesta pràctica de laboratori es pot transformar en un petit treball d'investigació sobre la influència que tenen diversos factors en la disminució de la quantitat de vitamina $C$.

Paraules clau: volumetria redox, vitamina C, suc de taronja, treball d'investigació

\section{Introducció} tres:

Els principals objectius d'aquesta activitat són

- treballar amb l'alumnat diversos conceptes del temari de la matèria de química de batxillerat

- que els estudiants coneguin la tècnica analítica de la volumetria redox

- i transformar una pràctica de laboratori en una activitat d'investigació.

D'aquesta manera s'intenta permetre que els alumnes treballin de manera semblant a com ho faria un científic.

El treball descrit a continuació va ser realitzat amb un grup d'alumnes de segon de batxillerat de la modalitat de ciències, dins de la programació de la matèria de química.

El professor va proposar el problema i va facilitar el mètode experimental per determinar el contingut de vitamina $C$ en les mostres de suc (volumetria redox amb 2,6-diclorofenol indofenol). L'alumnat va realitzar una recerca d'informació a través d'Internet per obtenir dades sobre les propietats de la vitamina C. A partir d'aquesta informació es va realitzar una discussió en grup a l'aula amb l'objectiu de dissenyar de manera conjunta una petita investigació per estudiar l'efecte de diversos factors (temperatura, llum, contacte amb l'aire) so- bre la quantitat de vitamina $\mathrm{C}$ present en un suc de taronja.

L'activitat es va desenvolupar al llarg de tres sessions de classe. En la primera es va plantejar el problema, es va realitzar la recerca inicial d'informació i es va discutir de manera conjunta el disseny de l'experiment. Es van necessitar dues sessions de laboratori per realitzar la preparació de les mostres i les anàlisis volumètriques.

\section{Fonament teòric}

La vitamina $C$ o àcid L-ascòrbic és un nutrient essencial requerit per reaccions metabòliques bàsiques. La majoria dels animals i les plantes són capaços de sintetitzar la seva pròpia vitamina $C$, excepte els simis (inclosos els humans), conills d'índies i algunes espècies d'ocells i ratpenats. La deficiència d'aquesta vitamina causa la malaltia de l'escorbut en els humans.

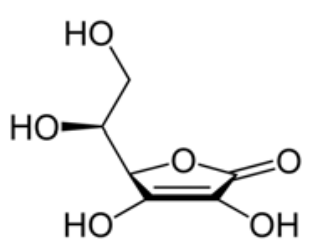

Figura 1. Estructura molecular de l'àcid L-ascòrbic 
L'àcid ascòrbic és una vitamina hidrosoluble i està present en grans quantitats en els sucs cítrics. És una substància que s'oxida amb relativa facilitat i això la converteix en un bon antioxidant natural amb una extensa aplicació com a additiu alimentari (té el codi E-300).

A temperatura ambient i en absència de catalitzadors enzimàtics, el procés d'oxidació de la vitamina $C$ és lent i la substància és bastant estable, especialment en medi àcid, que és com es troba en la majoria de fruites.

L'oxidació de la vitamina C s'accelera en presència de l'enzim àcid ascòrbic oxidasa. Qualsevol procés que provoqui el trencament de les cèl-lules de la fruita fa possible que aquest enzim s'alliberi i es barregi amb el suc. Com a resultat, la concentració de vitamina $\mathrm{C}$ disminueix ràpidament. Per altra banda, hi ha diversos factors ambientals que poden augmentar la velocitat del procés d'oxidació (augment de la temperatura, acció de la llum, contacte amb l'aire...).

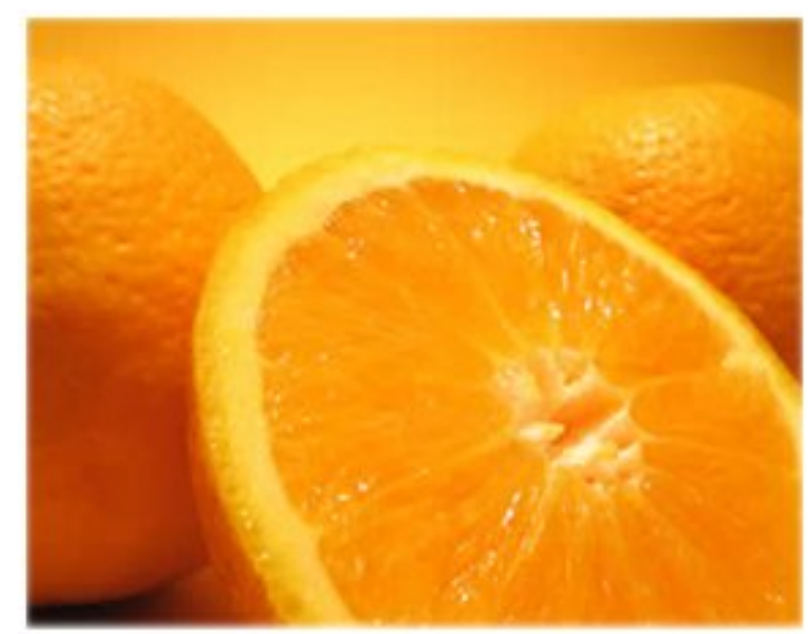

Figura 2. Diversos factors ambientals poden accelerar l'oxidació de la vitamina C.

\section{Volumetria redox}

Es pot determinar el contingut de vitamina $C$ en un suc realitzant una volumetria redox amb un agent oxidant que reaccioni amb tota la vitamina $C$ present en la mostra.

L'agent oxidant triat per realitzar aquesta anàlisi és el 2,6-diclorofenol indofenol (2,6-DCFIF). L'àcid ascòrbic és un gran reductor. Aquest poder reductor és degut a la pèrdua de dos àtoms d'hidrogen de la seva molècula que són captats pel 2,6DCFIF, que queda reduït. L'equació química de la reacció redox entre l'àcid ascòrbic i el 2,6-DCFIF és la següent:
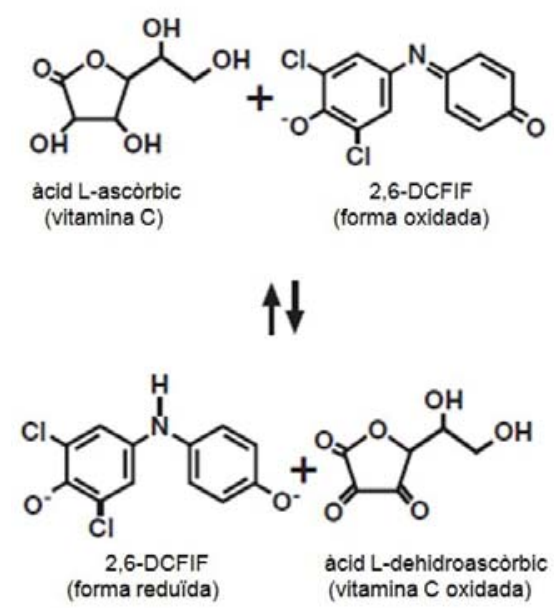

Figura 3. Reacció entre la vitamina C i el 2,6-diclorofenol indofenol.

Quan s'observi un viratge permanent, del color inicial de la mostra a un color vermell-rosat, anotarem el volum de colorant consumit. Després s'hauran de realitzar els càlculs pertinents per establir els mil.ligrams de vitamina $\mathrm{C}$ presents en cada $100 \mathrm{~mL}$ de suc.

\section{Material i equipament}

- Matrassos aforats de 100, 250 i $500 \mathrm{~mL}$

- Balança electrònica (és aconsellable que tingui una resolució de 0,01 g)

- Bureta de $25 \mathrm{~mL}$

- Matrassos erlenmeyer

- Suport metàl-lic amb pinça i nou

- Agitador magnètic (recomanable)

- Pipetes d'1, 5 i $10 \mathrm{~mL}$

- Aspiradors de pipetes

- Vas de precipitats

- Espremedora

- Colador

- Recipients diversos (envasos de vidre, brics)

\section{Reactius}

- Solució patró d'àcid ascòrbic (1000mg d'àcid ascòrbic per litre)

- Solució aquosa de colorant 2,6-DCFIF (sal sòdica) aproximadament $1 / 1000$

- Solució d'àcid oxàlic al $0,4 \%$

- Aigua desionitzada

- Taronges o suc de taronja comercial 


\section{Normes de seguretat i gestió dels residus}

El colorant 2,6-DCFIF pot provocar taques difícils d'eliminar a la pell i la roba. Cal evitar-hi el contacte.

Les restes de colorant i de les dissolucions obtingudes en finalitzar les valoracions és convenient dipositar-les en el contenidor de recollida selectiva de residus químics destinat als compostos orgànics halogenats.

\section{Estandardització del colorant}

Aquesta etapa del procediment és aconsellable que la realitzi el professor/a. El procediment que hem seguit per preparar el colorant, estandarditzarlo i realitzar la volumetria redox es basa en un guió facilitat pel senyor Saturnino Valle, de l'empresa Torrero i Mas de Barcelona, amb algunes modificacions.

En primer lloc s'ha de preparar la dissolució de colorant de concentració aproximadament 1/1000 (per exemple, 0,50 g de producte sòlid en $500 \mathrm{~mL}$ d'aigua desionitzada). Una vegada preparada i abans d'utilitzar-la, és convenient filtrar la dissolució per eliminar les restes de pols que puguin quedar sense dissoldre. Les dissolucions de 2,6-DCFIF tenen una vida relativament curta, uns 15 dies, i per això s'han de utilitzar immediatament.

També s'ha de preparar una solució patró d'àcid ascòrbic. En el nostre cas es van dissoldre 0,10 g d'àcid ascòrbic en 100 mL de dissolució (1000 mg d'àcid ascòrbic per cada litre de dissolució).

La tercera dissolució que s'ha de preparar és la solució d'àcid oxàlic $0,4 \%$ en massa.

En un matràs erlenmeyer es posen $1 \mathrm{~mL}$ de solució patró d'àcid ascòrbic (aquest mil.lilitre conté 1 mg de vitamina C) i $10 \mathrm{~mL}$ de solució d'àcid oxàlic $0,4 \%$.

Amb la bureta es va afegint la solució de colorant, agitant l'erlenmeyer al mateix temps (o amb l'ajuda d'un agitador magnètic). La valoració finalitza quan s'observa un viratge permanent d'incolor a vermell-rosat. Cal anotar el volum de solució de colorant gastat.

La relació "mL de colorant / mg d'àcid ascòrbic" es calcula tenint en compte que la solució patró d'àcid ascòrbic emprada conté 1000 mg d'àcid ascòrbic per cada litre de dissolució. En el nostre cas es va obtenir el següent resultat:

\author{
$12,2 \mathrm{~mL}$ colorant \\ $\mathrm{X}$ \\ $1 \mathrm{~mL}$ solució patró àcid ascòrbic \\ x $1000 \mathrm{~mL}$ solució patró àcid ascòrbic $=$ \\ 1000 mg àcid ascòrbic
$=12,2 \mathrm{~mL}$ colorant mg àcid ascòrbic

\section{Determinació del contingut de vitamina $C$}

La primera part del treball pràctic consisteix en determinar el contingut de vitamina $\mathrm{C}$ d'una mostra de suc de taronja.

En la nostra experiència, en comptes de treballar amb un suc de taronja comercial, es va optar per analitzar el suc obtingut de taronges recent espremudes. D'aquesta manera es volia evitar la possible presència d'additius.

Amb ajuda d'una espremedora es va extreure el suc de les taronges fins a obtenir-ne uns $500 \mathrm{~mL}$, volum suficient per preparar les diferents mostres que s'analitzarien en la segona part de la investigació. És convenient passar el suc a través d'un colador per eliminar les restes sòlides.

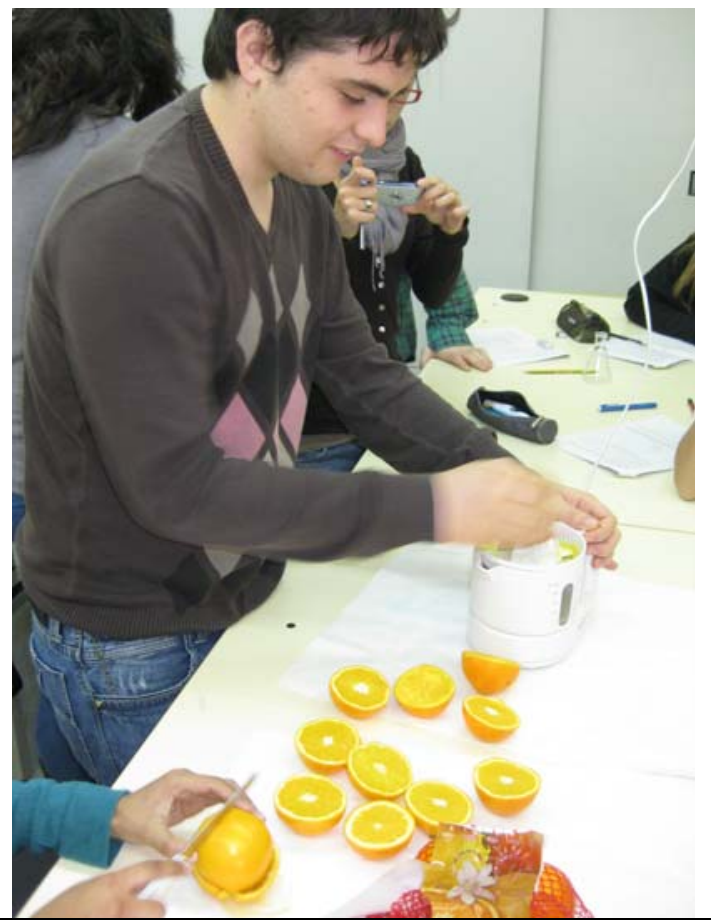

Figura 4. En aquesta experiència es va optar per analitzar el suc de taronges recent espremudes. 
Amb una pipeta s'agafen $5 \mathrm{~mL}$ del suc filtrat i es posen dins d'un matràs erlenmeyer amb $10 \mathrm{~mL}$ de solució d'àcid oxàlic al 0,4\%.

Es realitza la valoració amb el colorant 2,6DCFIF i s'anota el volum de colorant consumit. Es pot realitzar una segona valoració o utilitzar els resultats obtinguts pels diferents grups de treball, agafant el valor mitjà com a resultat de la volumetria. La taula 1 mostra els resultats obtinguts pels cinc grups d'alumnes que van realitzar l'experiència:

\begin{tabular}{|c|c|}
\hline Grup & $\mathbf{V}_{\text {colorant }}(\mathbf{m L})$ \\
\hline 1 & 6,9 \\
\hline 2 & 6,9 \\
\hline 3 & 6,9 \\
\hline 4 & 6,8 \\
\hline 5 & 6,9 \\
\hline
\end{tabular}

Taula 1. Volum de colorant utilitzat en la valoració.

Després es fan els càlculs necessaris per determinar la quantitat de vitamina $C$ present en la mostra de suc analitzada, expressant el resultat en mg de vitamina $\mathrm{C}$ en $100 \mathrm{~mL}$ de suc:

\section{$6,9 \mathrm{~mL}$ colorant $\times 1 \mathrm{mg}$ àcid asc. $\times 100 \mathrm{~mL}$ suc $=$}

$$
5 \mathrm{~mL} \text { suc } 12,2 \mathrm{~mL} \text { color. }
$$

\section{$=11,3 \mathrm{mg}$ vitamina $\mathrm{C}$ en $100 \mathrm{~mL}$ de suc}
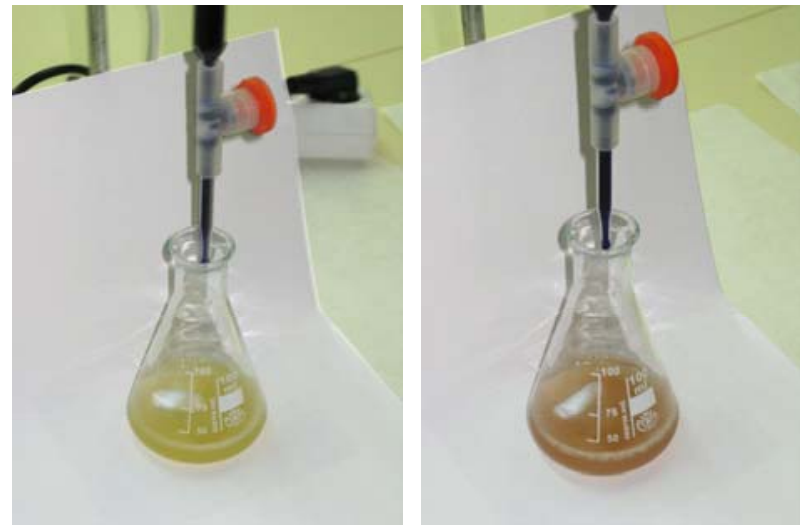

Figura 5. Canvi de color en el punt final de la volumetria.

\section{Estudi de l'efecte de diversos factors sobre el contingut de vitamina $C$}

\section{Disseny de l'experiment}

Durant la seva recerca d'informació, l'alumnat va trobar que la vitamina $C$ pot degradar-se per oxidació i que aquest procés es pot veure accelerat per diversos factors. El professor va demanar als estudiants que, a partir d'aquesta informació, proposessin com es podria dissenyar un experiment per estudiar en quina mesura afecten aquests factors a la quantitat de vitamina $\mathrm{C}$ present en el suc de taronja.

Després d'una discussió en grup, els alumnes van proposar preparar diverses mostres del mateix suc i sotmetre cada mostra a unes condicions diferents durant un temps determinat (una setmana). Després d'aquest temps s'analitzarien de nou les mostres per comprovar si s'havia produït alguna variació en el contingut de vitamina $\mathrm{C}$.
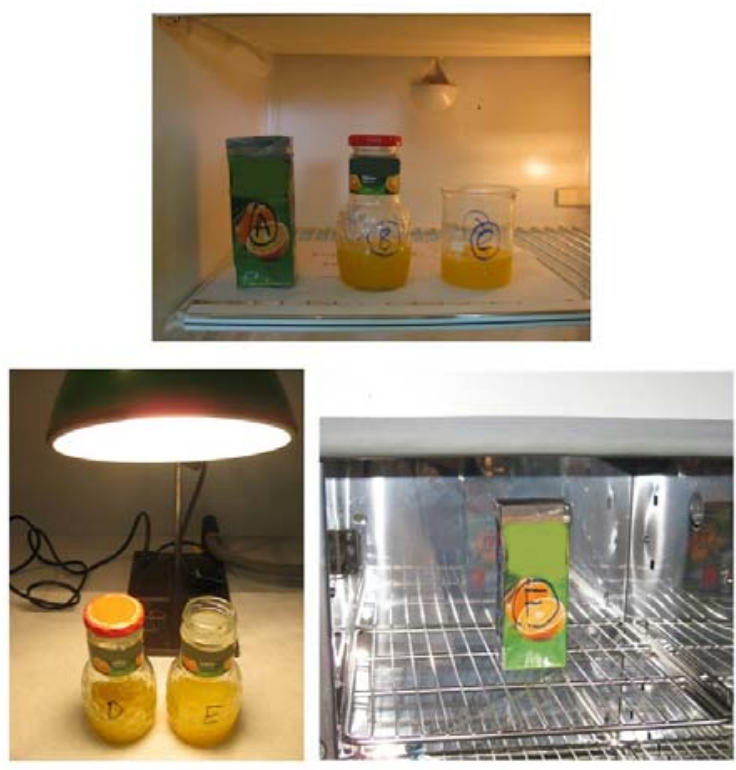

Figura 6. Les sis mostres de suc, sotmeses a diverses condicions.

\section{Descripció de les mostres}

El suc obtingut de les taronges es va distribuir en sis recipients i cada mostra es va sotmetre a unes condicions diferents durant una setmana. 
- Mostra A:

recipient opac (bric) tancat, a la nevera $\left(4^{\circ} \mathrm{C}\right)$

- Mostra B:

recipient de vidre tancat, a la nevera $\left(4^{\circ} \mathrm{C}\right)$

- Mostra C:

recipient de vidre obert, a la nevera $\left(4^{\circ} \mathrm{C}\right)$

- Mostra D:

recipient de vidre tancat sotmès a l'acció d'un focus de llum blanca

- Mostra E:

recipient de vidre obert sotmès a l'acció d'un focus de llum blanca

- Mostra F:

recipient opac (bric) tancat, a l'estufa $\left(40^{\circ} \mathrm{C}\right)$

\section{Resultats obtinguts}

Després d'una setmana es van analitzar de nou les mostres de suc. Els resultats es mostren a la taula 2:

\begin{tabular}{|c|c|c|c|}
\hline Mostra & $\begin{array}{c}\text { Volum } \\
\text { colorant } \\
\text { (mL) }\end{array}$ & $\begin{array}{c}\text { Contingut vita- } \\
\text { mina C } \\
\text { (mg/100 } \mathbf{~ m L} \\
\text { suc) }\end{array}$ & $\begin{array}{c}\text { Disminució con- } \\
\text { tingut } \\
\text { vitamina C (\%) }\end{array}$ \\
\hline $\mathrm{A}$ & 6,9 & 11,3 & 0 \\
\hline $\mathrm{B}$ & 6,9 & 11,3 & 0 \\
\hline $\mathrm{C}$ & 6,9 & 11,3 & 0 \\
\hline $\mathrm{D}$ & 5,4 & 8,9 & 21 \\
\hline $\mathrm{E}$ & 4,9 & 8,0 & 29 \\
\hline $\mathrm{F}$ & 1,1 & 1,8 & 84 \\
\hline
\end{tabular}

Taula 2. Resultats després d'una setmana.

\section{Anàlisi dels resultats i conclusions de l'alumnat}

Es va demanar als estudiants que realitzessin una anàlisi dels resultats obtinguts i que redactessin les conclusions a les que havien arribat. A continuació es reprodueix una selecció de les aportacions dels diferents grups d'alumnes:

- Les mostres conservades a la nevera a $4{ }^{\circ} \mathrm{C}$ han mantingut intacte el seu contingut de vitamina C. Sembla clar que les baixes temperatures aturen el procés d'oxidació de la vitamina.

- Les mostres sotmeses a la llum han experimentat una disminució important de la quantitat de vitamina (21\% i $29 \%$ ). Aquesta disminució ha estat superior en la mostra que, a més d'estar sotmesa a la llum, era en un recipient obert $i$ per tant ha estat en contacte amb l'aire.

- La pèrdua més important de vitamina $C(84 \%$ de disminució) s'ha produït en la mostra que ha estat sotmesa a una temperatura de $40^{\circ} \mathrm{C}$ dins de l'estufa.
- Un grup d'alumnes planteja que es podria haver preparat i analitzat una mostra més: suc contingut en un bric tancat i a temperatura ambient durant una setmana. Aquesta és una de les situacions més habituals de conservació dels sucs i no s'havia tingut en compte en el moment de dissenyar l'experiment.

\section{Proposta de qüestionari}

També es va proposar als alumnes que busquessin informació i responguessin a una sèrie de qüestions. Les respostes al qüestionari s'havien d'incloure en l'informe final de l'activitat:

- Per què s'afegeix una dissolució d'àcid oxàlic a les mostres abans de procedir a la volumetria?

- Per què les dissolucions de 2,6-diclorofenol indofenol tenen una vida tan curta i s'han d'utilitzar immediatament després de ser preparades?

- A partir dels resultats obtinguts indica de manera raonada quines penses que poden ser les millors condicions de conservació i el tipus d'envàs més adient per preservar el contingut de vitamina $C$ d'un suc de fruita.

- Mira l'envàs de diferents marques comercials de suc de taronja (pots anar a una botiga o a un supermercat). Anota el contingut de vitamina $C$ (expressat en mg de vitamina $C$ en $100 \mathrm{~mL}$ de suc) de cada marca. Recull tota la informació en una taula com l'adjunta i compara les dades. A quines conclusions pots arribar?

\begin{tabular}{|c|c|c|c|c|}
\hline $\begin{array}{c}\text { Marca } \\
\text { comer- } \\
\text { cial }\end{array}$ & $\begin{array}{c}\text { Contingut } \\
\text { vitamina C } \\
\text { (mg/100 mL } \\
\text { suc) }\end{array}$ & $\begin{array}{c}\text { Tipus } \\
\text { d'envàs } \\
\text { (tetrabrick, } \\
\text { plàstic, vidre, } \\
\text { etc.) }\end{array}$ & $\begin{array}{c}\text { Capacitat } \\
\text { envàs } \\
\text { (mL) }\end{array}$ & $\begin{array}{c}\text { Preu } \\
\text { (€/litre) }\end{array}$ \\
\hline & & & & \\
\hline & & & & \\
\hline & & & & \\
\hline
\end{tabular}

- Una altra informació que apareix en l'etiqueta d'informació nutricional dels envasos de suc de fruita i d'altres aliments rics en vitamines és el percentatge de la "QDR" (en castellà "CDR") que aporta l'aliment. Busca informació i explica el significat de la "QDR".

\section{Criteris d'avaluació}

Per avaluar l'activitat es poden tenir en compte els aspectes següents:

- La participació de l'alumnat en la recerca d'informació, la discussió del problema, l'emissió 
d'hipòtesis i la formulació de propostes per realitzar el disseny de l'experiment.

- La presentació d'un informe on figurin els diferents apartats que s'han treballat: objectius, informació sobre les propietats de la vitamina C, discussió del problema, disseny de l'experiment, material i equipament, reactius, procediment, anàlisi dels resultats, resposta a les preguntes del qüestionari i conclusions.

\section{Consideracions finals}

En l'activitat descrita en aquest article el professor ha proporcionat el problema a investigar i la tècnica analítica; l'alumnat ha participat en la planificació de l'experiment i l'obtenció de la "resposta" (anàlisi de resultats i conclusions). Aquesta seria una activitat experimental de nivell d'investigació 1,5 segons el marc d'anàlisi proposat per Herron (1971) i Tamir (1989) i modificat per J. Broto (2003), que es mostra a la taula 3.

\begin{tabular}{|c|c|c|c|}
\hline \multirow{2}{*}{$\begin{array}{c}\text { Nivell } \\
\text { d'investi- } \\
\text { gació }\end{array}$} & \multicolumn{3}{|c|}{ Qui proporciona... } \\
\hline & $\begin{array}{c}. . \text { el problema } \\
\text { a } \\
\text { Investigar? }\end{array}$ & $\begin{array}{l}\text {... el disseny } \\
\text { experimental? }\end{array}$ & ...la resposta? \\
\hline 0 & $\begin{array}{l}\text { El professorat } \\
\text { o el llibre de } \\
\text { text }\end{array}$ & $\begin{array}{l}\text { El professorat o } \\
\text { el llibre de text }\end{array}$ & $\begin{array}{l}\text { El professorat o } \\
\text { el llibre de text }\end{array}$ \\
\hline 1 & $\begin{array}{l}\text { El professorat } \\
\text { o el llibre de } \\
\text { text }\end{array}$ & $\begin{array}{l}\text { El professorat o } \\
\text { el llibre de text }\end{array}$ & L'alumnat \\
\hline 1,5 & $\begin{array}{l}\text { El professorat } \\
\text { o el llibre de } \\
\text { text }\end{array}$ & $\begin{array}{l}\text { Professorat: } \\
\text { dóna la llista de } \\
\text { material } \\
\text { Alumnat: plani- } \\
\text { fica } \\
\text { l'experiment }\end{array}$ & L'alumnat \\
\hline 2 & $\begin{array}{l}\text { El professorat } \\
\text { o el llibre de } \\
\text { text }\end{array}$ & L'alumnat & L'alumnat \\
\hline 2,5 & L'alumnat & $\begin{array}{l}\text { El professorat o } \\
\text { el llibre de text }\end{array}$ & L'alumnat \\
\hline 3 & L'alumnat & L'alumnat & L'alumnat \\
\hline
\end{tabular}

Taula 3. Marc d'anàlisi per a determinar el nivell d'investigació d'un treball experimental

Les sessions de classe dedicades a l'experiència s'haurien d'ampliar si es vol transformar el treball en una investigació de nivell 2 . En aquest cas caldria que siguin els estudiants els que realitzin una recerca d'informació per buscar quines són les tècniques que permeten realitzar la determinació de la vitamina $C$ en el tipus de mostres estudiades $i$ després triar la més adequada per aconseguir els objectius plantejats, tenint en compte que haurà de ser una tècnica assequible pel laboratori d'un centre d'educació secundària.

És evident que transformar una pràctica de laboratori en un treball d'investigació requereix una inversió de temps addicional. Per fer compatible la realització de treballs pràctics d'un nivell d'investigació més elevat amb el temps disponible per desenvolupar el currículum establert, es poden plantejar diverses alternatives:

- Una possibilitat seria realitzar menys pràctiques de laboratori al llarg del curs però que les que es facin impliquin un nivell de participació més elevat per part dels estudiants.

- Una altra opció seria proposar, des de cadascuna de les matèries de modalitat que cursen els alumnes del batxillerat científic (biologia, física, química), activitats d'investigació almenys en un parell d'ocasions durant cada curs. D'aquesta manera s'estaria garantint que al llarg de l'etapa l'alumnat realitza un nombre rellevant de treballs investigatius.

- Els treballs de recerca de batxillerat són una oportunitat excel-lent per plantejar activitats experimentals més obertes. Moltes pràctiques de laboratori es poden transformar en el punt de partida d'interessants treballs de recerca. En realitzar-se de manera individual o en petits grups d'alumnes, i en disposar de més temps per a la seva realització, els treballs de recerca permeten planificar de manera conjunta la investigació a partir del diàleg entre el professor i l'estudiant.

\section{Referències}

BROTO, J. (2003). Fotosíntesi. Centre de Documentació i Experimentació en Ciències i Tecnologia (article en línia, consulta desembre del 2010). http://www.xtec.es/sgfp/matform/multilog/biologi a/prof/Fotos\%EDntesi.pdf

http://milksci.unizar.es/bioquimica/temas/vitamins/a scorbico.html (consulta març 2011)

http://www.chemistryreact.org/go/Tutorial/Tutorial_22827.html (consulta març 2011) 